\title{
Strategic Technology Policy as a Supplement to Renewable Energy Standards
}

\author{
Carolyn Fischer \\ Mads Greaker \\ Knut Einar Rosendahl
}

\author{
CESIFO WORKING PAPER NO. 5710 \\ CATEGORY 10: ENERGY AND CLIMATE ECONOMICS \\ JANUARY 2016
}

An electronic version of the paper may be downloaded

- from the SSRN website:

- from the RePEc website:

- from the CESifo website:

www.SSRN.com

www.RePEc.org

www.CESifo-group.org/wp

\section{CESifo}




\title{
Strategic Technology Policy as a Supplement to Renewable Energy Standards
}

\begin{abstract}
In many regions, renewable energy targets are a primary decarbonization policy. Most of the same jurisdictions also subsidize the manufacturing and/or deployment of renewable energy technologies, some being sufficiently aggressive as to engender WTO disputes. We consider a downstream energy-using product produced competitively but not traded across regions, such as electricity or transportation. A renewable energy technology is available, provided by a limited set of upstream suppliers who exercise market power. With multiple market failures (emissions externality and imperfect competition), renewable market share targets as the binding climate policy, and international trade in equipment, the stage is set to examine rationales for green industrial policy. Subsidies may be provided downstream to energy suppliers and/or upstream to technology suppliers; each has tradeoffs. Subsidies can offset underprovision upstream, but they allow dirty generation to expand when the portfolio standard becomes less binding. Downstream subsidies raise all upstream profits and crowd out foreign emissions. Upstream subsidies increase domestic upstream market share but expand emissions globally. In our two-region model, strategic subsidies chosen noncooperatively can be optimal from a global perspective, if both regions value emissions at the global cost of carbon. But if the regions sufficiently undervalue global emissions, restricting the use of upstream subsidies can enhance welfare.
\end{abstract}

JEL-codes: Q500.

\author{
Carolyn Fischer \\ Resources for the Future \\ USA - Washington, D.C. 20036 \\ fischer@rff.org
}

\author{
Mads Greaker \\ Statistics Norway \\ Norway - 0033 Oslo \\ mgr@ssb.no
}

\author{
Knut Einar Rosendahl \\ Norwegian University of Life Sciences \\ Norway-1432 As \\ knut.einar.rosendahl@nmbu.no
}

\begin{abstract}
We would like to thank the Norwegian Research Council's RENERGI program and the Mistra Foundation's ENTWINED program for financial support. Fischer would like to acknowledge the European Community's Marie Curie International Incoming Fellowship, 'STRATECHPOL - Strategic Clean Technology Policies for Climate Change', financed under the EC Grant Agreement PIIF-GA-2013-623783, and the hospitality of the Fondazione Eni Enrico Mattei (FEEM).
\end{abstract}




\section{Introduction}

Policymakers around the world are concerned about the problem of global climate change. Yet, while carbon pricing is considered the most cost-effective way to reduce carbon emissions, most if not all governments are hesitant to impose it in any form strict enough to produce the needed reductions. Rather, a variety of alternative instruments are introduced, including renewable energy targets, renewable portfolio standards (RPS), subsidies to $\mathrm{CO}_{2^{-}}$ free energy, efficiency standards, etc.

Examples of such policies are plentiful. In the United States (US), where the prospects for national $\mathrm{CO}_{2}$-pricing are weak, fuel efficiency standards and biofuels requirements are imposed nationally for the transport sector, and in the electricity sector the Obama administration has announced $\mathrm{CO}_{2}$ emission standards for existing power plants in the form of the Clean Power Plan. In addition, RPS are imposed in a majority of the states [21]. ${ }^{1}$ In the European Union (EU), although a cap-and-trade system is in place (EU ETS), member countries have also jointly agreed upon ambitious renewable energy targets, both in total consumption and in the transport sector, as well as upon energy efficiency targets. The Renewable Energy Directive (2009/28/EC) in particular is being credited with driving the transformation of the electricity sector, while the price of $\mathrm{CO}_{2}$ in the ETS remains low, due in part to supplementary goals and instruments [20], [2]. Lastly, China's Five Year Plan for 2011-2015 includes targets for the share of non-fossil fuels in primary energy consumption, in addition to targets regarding the energy intensity and emissions intensity of the economy

\footnotetext{
${ }^{1}$ Regional cap-and-trade systems for $\mathrm{CO}_{2}$-emissions are also in operation, but only in a minority of the states, and all in conjunction with overlapping RPS policies.
} 
[1].

Renewable energy targets can be achieved through market-based mechanisms such as blending mandates for biofuels and green certificates for renewable energy. Note that introducing such targets does not imply any direct payments from the government to the renewable energy suppliers; indeed, this revenue neutrality may play an important role in their political acceptability. At the same time, most governments also provide direct subsidies to renewable energy, both in the forms of additional adoption incentives and manufacturing and innovation incentives. However, such subsidies are beginning to raise suspicions within the framework of the World Trade Organization (WTO) rules, which place restrictions on industrial policies that distort trade. In one ruling, the WTO dispute panel found problems with Ontario's feed-in-tariff, which incorporated domestic content requirements [11]. In another set of cases, the EU and US have brought anti-dumping and anti-subsidy complaints against China, charging that large Chinese subsidies in the form of cheap loans, land, and capital to photovoltaic producers constitute illegal aid. According to the WTO, supporting the deployment and diffusion of green technologies is not hindered by WTO rules [27], but nonetheless concerns are growing about the need to properly define the appropriate parameters for green industrial policy.

In this paper, we examine the rationale for such supplementary subsidy policies when countries have already set in place renewable energy targets. By requiring that a certain share of energy be generated from renewable sources, renewable portfolio standards encourage deployment and create new profit opportunities for firms that supply renewable energy 
capital. They also reduce emissions to the extent they displace dirty energy sources. To what extent, then, do supplementary policies further contribute to these goals? In the EU and elsewhere, renewable support policies also reflect the belief that high environmental standards stimulate innovation and business opportunities, including for exports [8]. With imperfect competition among technology suppliers, supplementary technology policy could be used strategically to achieve such goals. To our knowledge, our paper is the first to analyze the case for green industrial policy in this context.

Moreover, it may matter for industrial policy whether subsidies are provided downstream or upstream i.e., to suppliers of electricity or transport fuels, or upstream, i.e., to suppliers of capital to produce renewable electricity or fuel. This is related to the demand pull versus technology push issue discussed with respect to innovation (see e.g. [19] and [26]). ${ }^{2}$ Our focus, however, is on industrial policy and $\mathrm{CO}_{2}$ emissions, and thus we disregard innovation externalities as well as other possible reasons to implement subsidies such as energy security (see e.g. [3]).

We approach these questions with analytical methods. In our theoretical analysis, we assume a closed and competitive downstream market in each country, which is reasonable for thinking of either the electricity or the transport sector in large countries or jurisdictions (EU, US, China etc.). On the other hand, we assume that upstream producers of technology equipment can both sell domestically and export to foreign regions. Furthermore, as the number of upstream suppliers is fairly small for most energy technologies, partly due to

\footnotetext{
${ }^{2}$ There is a large literature on innovation externalities in the context of environmental problems (see e.g. [?], [12], [15] and [16]).
} 
patent restrictions, the typical upstream market can hardly be considered competitive. ${ }^{3}$ In line with previous studies ([18], [14], [5], [22]), we assume Cournot competition between the upstream suppliers, with a uniform global price of technology equipment.

First, we find that a potential rationale for subsidies does exist. The rationale is partly due to imperfect competition among technology suppliers, which leads to underprovision if not corrected, and partly due to strategic interests in shifting the profit opportunities created by the renewable energy standards to national firms. Note that the renewable energy standard in itself implies a negative strategic effect, as it spurs foreign firms' supply of renewable energy capital. From a national strategic perspective, optimal subsidies then involve taxes downstream and positive subsidies upstream. Positive subsidies upstream provide the national upstream industry with an advantage, and addresses the market power issue. A downstream subsidy, on the other hand, reinforces the negative strategic effect from the renewable standard, and the government might want to tax the use of equipment.

Note that subsidizing renewable energy technology equipment will make the renewable portfolio standard easier to meet, and reducing this burden allows total energy productionand emissions - to increase. If the shadow costs of emissions are sufficiently high, the emission effect dominates the profit-shifting effect and the market power issue, implying that the upstream supply of renewable capital should also be taxed.

Second, we compare globally optimal policies to national strategic policies. From a global

\footnotetext{
${ }^{3}$ According to [22] the solar panel industry is imperfectly competive. The production of second generation biofuels also seems to be dominated by a few firms, see e.g. [7]. This is the case for wind turbine producers, too (see [24]). Finally, see [23] for more examples of imperfect competition in upstream markets for pollution abatement technology.
} 
perspective, in the symmetric case, it does not matter whether subsidies are introduced upstream or downstream. However, we show that the Nash equilibrium between symmetric countries can in fact lead to an optimal set of subsidies, provided that the individual countries each value domestic emissions by the global cost of carbon. From the strategic trade literature, we know that a Nash-equilibrium in subsidies tends to be a Prisoners Dilemma. We find that this is not necessarily the case when we have a transboundary environmental externality.

To our knowledge, the issue of strategic subsidies to renewable energy together with renewable energy standards in the electricity sector has not been analyzed before. Overlapping renewable energy policies have been studied in a single-region context (see, e.g., [12]; [13]; [2]), and several contributions study subsidies together with blending mandates for biofuels (see e.g. [6]). None of these contributions find positive welfare effects of subsidies; however, as they all assume perfect competition upstream and/or a single region, strategic aspects are absent. Strategic use of abatement technology policy has previously been analyzed in [4], [17] and [25]. However, these papers do not model the market for abatement technology explicitly, which becomes important for our conclusions, and which allows us to study industrial policy. While [18] and [14] do make this distinction, they consider different kinds of abatement technologies and environmental policies, leading to contrasting results, particularly with respect to the emissions consequences of overlapping policies. In fact, the issue that a binding renewable energy target also implies a binding nonrenewable energy share drives significant aspects of our results and highlights the importance of considering the 
policy context in evaluating supplemental and strategic policies.

In the next section we describe our analytical model, and derive some results with respect to market effects of renewable energy technology subsidies. Then, in Section 3 we analyze optimal subsidy policies, both from a global and national perspective. Section 4 concludes.

\section{The model}

The structure of the model is as follows: The world is divided into two regions, one domestic region (Region 1) and one foreign region (Region 2). Each region features a closed, downstream market for an energy product, which we can think of as, e.g., the electricity market. ${ }^{4}$ Both downstream markets consist of firms located and owned in the corresponding regions, and competition is perfect. Production of the energy product with conventional technology leads to emissions of some pollutant that may have cross-border damages (e.g., $\mathrm{CO}_{2}$ ). An alternative energy technology is available, such as solar panels, wind turbines, etc., that can produce the downstream energy product without emissions. This technology is supplied in an upstream market characterized by imperfect competition, which can be attributed to the nascent nature of the technology, intellectual property protection, and so forth. For simplicity, we assume that one upstream firm is located and owned in each of the two regions.

We assume that each region has a fixed, positive, and binding renewable energy standard, meaning that a certain share of total downstream supply must come from renewables. This standard is set before the game begins. If the standards differ, we assume that Region 1

\footnotetext{
${ }^{4}$ As mentioned above, we may also think of the market for transport fuels.
} 
has the higher standard. Renewable energy standards are common in the electricity sector of the EU and many US states, as well as in the transport sector.

In the first stage of the game, the supplementary environmental technology policies are set. We will distinguish between scenarios where these policies are set simultaneously in both regions, and scenarios where there are no such policies in Region 2. We consider two different types of environmental technology policy: The government can subsidize the use of renewable energy downstream, and it can subsidize the unit delivery costs of the upstream technology firms. We may think of this cost subsidy as the net effect of a range of policies, including direct subsidies, R\&D support etc. ${ }^{5}$

In the second stage of the game, the technology firms compete in Cournot fashion to supply renewable energy technology equipment (e.g. solar panels) to the downstream sector in both regions. Thus, the upstream technology firms sell in both foreign and domestic markets. Cournot competition is appropriate when firms supplying a particular type of patented equipment first determine production capacity and then decide on the price. The downstream firms have to comply with the region-specific renewable standards. Note that the standard does not apply to each individual firm, but to the sector as a whole. Compliance can be achieved by implementing market instruments such as RPS or tradable green certificates.

\footnotetext{
${ }^{5}$ The welfare effects of R\&D support may be different from the effects of direct subsidies. This is disregarded in our welfare analysis below as we do not focus on innovation externalities, but we acknowledge that they may constitute another interesting source of upstream market failures.
} 


\subsection{Downstream market for energy}

We treat the downstream sector in region $i$ as one representative firm, which we will call an electricity supplier. Let $q_{i}$ be the total output of the representative firm, and $x_{i}$ is the output coming from renewables (e.g., solar or wind power). ${ }^{6}$ Emissions $e_{i}$ from this firm are in proportion to nonrenewable generation, given by: $e_{i}=q_{i}-x_{i}$.

The renewable standard in region $i$ is denoted by $r_{i}$, such that $r_{i}=\frac{x_{i}}{q_{i}}$, i.e., $r_{i} \in[0,1\rangle$, and a higher $r_{i}$ implies a more stringent standard. We assume throughout the paper that each region's standard is binding, ${ }^{7}$ and that $r_{1} \geq r_{2}$. The necessary amount of renewables to reach the target in region $i$ is then:

$$
x_{i}=r_{i} q_{i}
$$

Let the regional demand for the downstream product be given by the inverse demand function $p_{i}=M-\varepsilon q_{i}$ where $\varepsilon \geq 0$. Note that, in order to simplify expressions, we assume identical demand functions in the two regions.

Let production costs of nonrenewable energy take a simple quadratic form, which gives us a linear, upward-sloping supply curve for nonrenewable energy, which can reflecting different capital vintages of nonrenewable energy or increasing input costs. Meanwhile, let renewable

\footnotetext{
${ }^{6}$ Note that we implicitly assume here that all nonrenewable energy use leads to emissions. In the context of the electricity sector, nuclear power is an exception; however, as nuclear operates as baseload generation with predetermined capacity, it can largely be thought of as exogenous.

${ }^{7} \mathrm{~A}$ sufficient condition for this to be the case at the outset is that $M /(1+\epsilon)<\rho$, where $M /(1+\epsilon)$ is the market price with no renewable production and $\rho$ is the unit cost of producing renewable energy (see below). Furthermore, we consider a range of supplementary policies that are not strong enough to render renewable standards nonbinding. This possibility is interesting but unlikely and outside the current scope.
} 
energy enter as a backstop technology, with a constant unit (levelized) cost of supply $\left(w-\eta_{i}\right)$, where $w$ denotes the world market price of technologies to produce renewable energy, and $\eta_{i}$ is the downstream subsidy on the use of such technology. The total costs of the representative downstream firm can then be expressed as:

$$
c_{i}\left(q_{i}\right)=\frac{\left(\left(1-r_{i}\right) q_{i}\right)^{2}}{2}+\left(w-\eta_{i}\right) r_{i} q_{i}
$$

where $\left(1-r_{i}\right) q_{i}$ is the production of nonrenewable energy.

The representative firm takes the downstream market price $p_{i}$ as given, and maximizes profit. This gives the following reduced form supply functions in the downstream markets (see Appendix A.1):

$$
q_{i}=\frac{M-r_{i}\left(w-\eta_{i}\right)}{R_{i}}
$$

where $R_{i}=\left(1-r_{i}\right)^{2}+\varepsilon$ is increasing in nonrenewable market share and the elasticity (slope) of downstream demand.

Clearly, downstream energy production in the home country is increasing in the domestic downstream subsidy, but decreasing in the global technology price $w$ (which itself responds to each region's subsidy policies; see Section 2.3 below) ${ }^{8}$

The production of renewable energy, which translates into demand for the renewable energy technology in the upstream sector (see the next subsection), follows straighforwardly

\footnotetext{
${ }^{8}$ The effect on $q_{i}$ of increasing the standard $r_{i}$ is ambiguous, and tends to be nonmonotonic. At modest targets, electricity output may either increase or decrease when $r_{i}$ rises. At sufficiently stringent targets, it is easy to show that $q_{i}$ will decline when $r_{i}$ rises (see [10] for a thorough discussion of this issue).
} 
from (1) and (3).

\section{$2.2 \quad$ Upstream supply of renewable energy technology}

Consider now the supply of the alternative energy technology. By "technology supply" we mean the supply of capacity to produce one unit of energy per time unit. Operating costs are disregarded (which is a reasonable simplification for renewable generation). We assume that one technology firm operates in each region, supplying both its home market as well as the foreign market. Let $y_{i}$ denote the supply of the firm located in Region $i$. We assume that the supply of technology takes place at constant unit costs $\left(\rho-\gamma_{i}\right)$, where $\rho$ denotes the levelized unit production cost and $\gamma_{i}$ the levelized upstream technology subsidy in Region $i^{9}$

Denote the total use of renewable energy technology by $x^{T}=x_{1}+x_{2}=r_{1} q_{1}+r_{2} q_{2}$. From (3) we know that $x^{T}$ is a function of the technology price $w$, as well as the downstream subsidies. To derive reduced form expressions for $w, y_{1}^{*}$ and $y_{2}^{*}$, we first express the function $x^{T}(w)$ as follows:

$$
x^{T}(w)=\frac{r_{1} M+\left(r_{1}\right)^{2} \eta_{1}}{R_{1}}+\frac{r_{2} M+\left(r_{2}\right)^{2} \eta_{2}}{R_{2}}-\left(\frac{\left(r_{1}\right)^{2}}{R_{1}}+\frac{\left(r_{2}\right)^{2}}{R_{2}}\right) w
$$

This function can be inverted to yield the inverse demand function for technology:

$$
w=A\left(r_{i}, \eta_{i}\right)-B\left(r_{i}\right) x^{T}, i=1,2
$$

\footnotetext{
${ }^{9}$ We use the term "levelized" in order to make the correct comparison between investment costs of renewables and production costs of nonrenewables.
} 
where $A, B$ are given by:

$$
\begin{aligned}
A\left(r_{i}, \eta_{i}\right) & =\frac{r_{1} R_{2}\left(M+\eta_{1} r_{1}\right)+r_{2} R_{1}\left(M+\eta_{2} r_{2}\right)}{\left(r_{1}\right)^{2} R_{2}+\left(r_{2}\right)^{2} R_{1}} ; \\
B\left(r_{i}\right) & =\frac{R_{1} R_{2}}{\left(r_{1}\right)^{2} R_{2}+\left(r_{2}\right)^{2} R_{1}}
\end{aligned}
$$

and $R_{i}=\left(\left(1-r_{i}\right)^{2}+\varepsilon\right)$. Note that $A$ is increasing in the downstream subsidies, while $B$ is independent of the downstream subsidies.

Assuming that total demand for renewable energy technology in the two regions equals total supply, we can derive the following Nash-equilibrium supply of technology:

$$
y_{i}=\frac{A-\rho+2 \gamma_{i}-\gamma_{j}}{3 B} \quad(i \neq j)
$$

By summing over $i$, we compute $x^{T}=\left(2(A-\rho)+\gamma_{1}+\gamma_{2}\right) / 3 B$, from which we find the technology price:

$$
w=\frac{A+2 \rho-\gamma_{1}-\gamma_{2}}{3}
$$

It will be useful to note that the case of symmetric regions and downstream policies, the technology price simplifies to $w=\left(M / r+2 \rho+\eta-\gamma_{1}-\gamma_{2}\right) / 3$.

From the above expressions and in the previous subsection, we can derive the effects of upstream and downsteam subsidies on supply and demand for technology, and on the price of the technology. 


\subsection{Effects of technology policies}

First, we consider the effects on the technology price, where we have the following proposition:

1 An increase in the downstream subsidy in any region will increase the global technology price, while an increase in the upstream technology subsidy in any region will decrease the technology price.

Proof. This follows from (6) and the expression for $A\left(r_{i}, \eta_{i}\right)$. See Appendix A.2.1 for a formal proof.

We notice that the two subsidies have opposite effects on the technology price. Furthermore, the downstream subsidy has a weaker impact, cf. the Appendix. These results have importance for the quantity effects upstream and downstream, and have crucial implications for optimal subsidy levels when seen from a national strategic perspective (see next section).

Next, we consider the effects on upstream supply:

2 An increase in the downstream subsidy in any region will increase output of both upstream firms. An increase in the upstream technology subsidy in one region will increase output of the upstream firm in this region, decrease output of the upstream firm in the other region, and increase total output in the upstream market.

Proof. This follows from (5) and the expression for $A\left(r_{i}, \eta_{i}\right)$. See Appendix A.2.2 for a formal proof.

That is, a higher upstream subsidy crowds in production by the home firm and crowds out production by the foreign one, whereas a higher downstream subsidy induces both upstream 
firms to increase their supply of technology.

Finally, we turn to the downstream market, where we find:

3 An increase in the downstream subsidy in one region will increase output and emissions of the downstream firm in this region, decrease output and emissions of the downstream firm in the other region, and increase total output and emissions downstream. An increase in the upstream technology subsidy in any region will increase output and emissions of the downstream firms in both regions.

Proof. See Appendix A.2.3.

We note that a downstream subsidy in one region also affects the downstream market in the other region, even in the absence of trade between the downstream markets. The explanation is that the markets are linked through the upstream technology market: a higher downstream subsidy increases the upstream price and hence increases the costs of producing energy in the region with no subsidy change. Hence, output falls. Total output in the two markets must increase, however (see the proof of the proposition). Furthermore, since both downstream markets are regulated with a portfolio standard, an increase in overall output implies an increase in nonrenewable as well as renewable output, and thereby an increase in emissions.

\section{Optimal and strategic environmental technology policies}

We now consider optimal technology policies, first from a global perspective and then from a domestic perspective in Region 1. As before, we assume that each region has committed 
to a fixed renewable standard $r_{i}$ for its downstream sector. With a regional perspective, we assume that domestic emissions reductions are valued at a price $\tau_{i} \geq 0$, whereas foreign emissions are valued at a price $\beta_{i} \tau_{i}$, where $0 \leq \beta_{i} \leq 1$. With a global perspective we assume that emissions reductions in the two regions are valued at the same price, $\tau_{G}>0$, as is the case with greenhouse gases. Thus, with $\tau_{i} \leq \tau_{G}$ and $\beta_{i} \leq 1$, we allow for the possibility that an individual region places a lower value on emissions than the global social cost and that it may further discount emissions coming from outside its jurisdiction (which may be seen as less relevant for its contribution to global emissions reductions).

Welfare in Region $i$ then equals:

$$
\begin{aligned}
W_{i}= & \underbrace{\frac{\varepsilon\left(q_{i}\right)^{2}}{2}}_{\text {Downstream profits }}+\underbrace{\left(M-\varepsilon q_{i}\right) q_{i}-\frac{\left(1-r_{i}\right)^{2}\left(q_{i}\right)^{2}}{2}-\left(w-\eta_{1}\right) r_{i} q_{i}}_{\text {Consumer surplus }}+\underbrace{\left(w-\rho+\gamma_{i}\right) y_{i}}_{\text {Upstream profits }} \\
& -\underbrace{\left(\eta_{i} r_{i} q_{i}+\gamma_{i} y_{i}\right)}_{\text {Subsidy costs }}-\underbrace{\left(\tau_{i}\left(1-r_{i}\right) q_{i}+\beta_{i} \tau_{i}\left(1-r_{j}\right) q_{j}\right)}_{\text {Emissions costs }}
\end{aligned}
$$

We assume that parameter values are such that the second-order derivatives of the welfare function are negative and hence, that a maximum exists.

\subsection{Globally optimal technology policies}

As a reference point, it is useful to begin with a global perspective. Given renewable standards, global welfare depends entirely on final downstream output in each region.

\subsubsection{Optimal global policies}

The expression for regional welfare in (7) can be simplified as follows: 


$$
M q_{i}-R_{i} \frac{\left(q_{i}\right)^{2}}{2}+w\left(y_{i}-r_{i} q_{i}\right)-\rho y_{i}-\tau_{i}\left(1-r_{i}\right) q_{i}-\beta_{i} \tau_{i}\left(1-r_{j}\right) q_{j}
$$

where $R_{i}=\left(\left(1-r_{i}\right)^{2}+\varepsilon\right)$.

Global welfare equals the sum of the regional welfares, adjusting for any undervalued damages, so

$$
W_{G}=M\left(q_{1}+q_{2}\right)-R_{1} \frac{\left(q_{1}\right)^{2}}{2}-R_{2} \frac{\left(q_{2}\right)^{2}}{2}-\rho\left(r_{1} q_{1}+r_{2} q_{2}\right)-\tau_{G}\left(\left(1-r_{1}\right) q_{1}+\left(1-r_{2}\right) q_{2}\right)
$$

Note that in (9), we are left with only the real cost of production; that is, the price $w$ of renewable energy technologies cancels out.

Differentiating global welfare $W_{G}$ gives:

$$
d W_{G}=\left(M-R_{1} q_{1}-\rho r_{1}-\tau_{G}\left(1-r_{1}\right)\right) d q_{1}+\left(M-R_{2} q_{2}-\rho r_{2}-\tau_{G}\left(1-r_{2}\right)\right) d q_{2}
$$

As global welfare effects depend on how a policy change affects $q_{1}$ and $q_{2}$, the optimal output levels downstream (leading to $d W_{G} / d q_{1}=d W_{G} / d q_{2}=0$ ), for given levels of $r_{i}$, are:

$$
q_{i}^{*}=\frac{M-\rho r_{i}-\tau_{G}\left(1-r_{i}\right)}{R_{i}} .
$$

Using the decentralized equilibrium value of $q_{i}$ in (3)), we can derive an expression for the optimal "net" (after-subsidy) technology price in the downstream market: 


$$
w-\eta_{i}=\rho+\left(\frac{1}{r_{i}}-1\right) \tau_{G}, i=\{1,2\} .
$$

That is, in each region, the net cost of renewable technology to the downstream producer equals the marginal cost of production plus a term reflecting the external costs of additional renewable energy in each region - namely, the additional output of nonrenewable energy. Due to the binding RPS, increased output of renewable energy comes along with increased output of nonrenewable energy, and thus higher emissions. Hence, the planner only partly offsets the markup from imperfect competition. ${ }^{10}$

In (12), we have just two equations for four variables for determining the optimal combination of downstream and upstream subsidies (recalling that $w$ is a function of all of these). The global planner is thus generally indifferent between using upstream or downstream subsidies or both, as long as the downstream prices in (12) are achieved. If RPS targets differ, then the downstream subsidy (or tax) must be differentiated among the two regions, however.

For example, if we assume that the countries are identical (including $r_{1}=r_{2}$ ), the optimal subsidy combination would be symmetric and using (6):

$$
\eta+\gamma=\frac{M-\rho r-3 \tau_{G}(1-r)}{2 r}
$$

The sign of this expression is in general ambiguous. The first two parts in the numerator

\footnotetext{
${ }^{10}$ If the renewable standard were replaced by an emissions cap, costs of emissions would be unchanged by the subsidies. With an emissions tax, cheaper renewable technology would lead to additional abatement, calling for an additional benefit from the subsidies if the tax rate were below $\tau$.
} 
are jointly positive, whereas the last part is negative. We see that for sufficiently low $\tau_{G}$ or sufficiently high $r$, the expression must be positive, meaning in this case that the sum of all subsidies must be positive. The reason is that the extra emissions costs are negligible and thus the market power issue dominates. On the other hand, if the additional emissions costs are sufficiently high (high $\tau_{G}$ and low $r$ ), the sum of all subsidies should be negative.

We state these results in the following proposition:

4 When the downstream sectors are regulated with a renewable standard, an optimal strategy from a global persective is to introduce upstream and downstream subsidies that together are positive to the extent that the value of correcting the upstream market failure exceeds the additional emissions costs. Further, the downstream subsidy will be higher in the region with the more stringent renewable energy target.

\subsubsection{Optimal unilateral policies}

Alternatively, suppose the planner cannot set subsidies in Region 2, but only in Region 1 . The planner can still achieve the optimal outcome with its remaining two policy tools. From (12), we have two equations and two variables. The planner will want to use a downstream subsidy in Region 1 to balance that in Region 2 and to adjust for any differences in RPS targets:

$$
\eta_{1}^{U}=\eta_{2}^{U}+\left(\frac{1}{r_{2}}-\frac{1}{r_{1}}\right) \tau_{G}
$$

In other words, the downstream subsidy is larger to the extent that Region 1 has a more ambitious RPS policy, and to the extent that Region 2 subsidizes downstream use of the 
technology. This serves to shift renewable technology adoption towards the region where nonrenewable energy will expand less.

Since technology production costs are identical across the regions, the planner does not care where the equipment is produced. Further, recall that $\partial w / \partial \gamma_{1}=\partial w / \partial \gamma_{2}$ (cf. (6)). Given any upstream subsidy in Region 2, the planner thus adjusts $\gamma_{1}^{U}$ to ensure that the targeted downstream prices in (12) hold. Thus, there is a unique solution for $\gamma_{1}^{U} \cdot{ }^{11}$

We summarize these results in the following proposition:

5 When the downstream sectors are regulated with renewable standard, the optimal unilateral strategy from a global perspective is to implement a downstream subsidy in Region 1 in excess of that set by Region 2 to the extent that the former region has a higher renewable target, and to implement an upstream subsidy in Region 1 to bring downstream net-of-subsidy prices in line with their marginal social costs.

\subsection{Strategic technology policies}

An individual country does not maximize global welfare but its own. Totally differentiating (8), and using (3) to simplify, we have the following change in regional welfare from a policy change:

$$
d W_{i}=\underbrace{-\left(r_{i} \eta_{i}+\tau_{i}\left(1-r_{i}\right)\right) d q_{i}}_{\text {additional subsidy and emissions cost }}+\underbrace{\left(y_{i}-r_{i} q_{i}\right) d w}_{\text {terms of trade effect }}+\underbrace{(w-\rho) d y_{i}}_{\text {upstream profit change }}-\underbrace{\beta_{i} \tau_{i}\left(1-r_{j}\right) d q_{j}}_{\text {leakage costs }}
$$

\footnotetext{
${ }^{11}$ It can be easily solved algebraically, but the expression is complex providing little intuition.
} 
We see that the marginal incentives are quite different than those from the global perspective. For instance, to the extent that the region has a trade surplus in renewable technologies, welfare increases if the price $w$ increases (second term in (14)). Also, welfare increases if production of renewable technology $y_{i}$ expands since there is a mark-up over costs in the upstream industry (third term in (14)).

\subsubsection{Regional Nash equilibrium}

Using (3), (5) and (6), we can express the regional welfare change from a change in the upstream subsidy as follows:

$\frac{d W_{i}}{d \gamma_{i}}=\left(r_{i} \eta_{i}+\tau_{i}\left(1-r_{i}\right)\right) \frac{r_{i}}{R_{i}} \frac{d w}{d \gamma_{i}}+\left(y_{i}-r_{i} q_{i}\right) \frac{d w}{d \gamma_{i}}-(w-\rho) \frac{2}{B} \frac{d w}{d \gamma_{i}}+\beta_{i} \tau_{i}\left(1-r_{j}\right) \frac{r_{j}}{R_{j}} \frac{d w}{d \gamma_{i}}, i=1,2$

where $R_{i}$ is specified above (see (8)). Similarly, we derive the welfare change from a change in the downstream subsidy:

$\frac{d W_{i}}{d \eta_{i}}=-\left(r_{i} \eta_{i}+\tau_{i}\left(1-r_{i}\right)\right) \frac{r_{i}}{R_{i}}\left(1-\frac{d w}{d \eta_{i}}\right)+\left(y_{i}-r_{i} q_{i}\right) \frac{d w}{d \eta_{i}}+(w-\rho) \frac{1}{B} \frac{d w}{d \eta_{i}}+\beta_{i} \tau_{i}\left(1-r_{j}\right) \frac{r_{j}}{R_{j}} \frac{d w}{d \eta_{i}}, i=1,2$

Setting $d W_{i} / d \gamma_{i}=d W_{i} / d \eta_{i}=0$, we obtain the Nash equilibrium. Unlike the global perspective, which can reach the optimal outcome with a range of subsidy combinations, in the regional Nash equilibrium, the solution is unique (we have four equations and four policy variables). By rearranging the expression for $d W_{i} / d \eta_{i}=0$, the expression for the Nash equilibrium downstream subsidy becomes: 


$$
\eta_{i, N}=-\tau_{i}\left(\frac{1}{r_{i}}-1\right)+\tau_{i} \beta_{i}\left(\frac{1}{r_{j}}-1\right) \frac{\alpha_{j}}{2-\alpha_{i}}+\left(y_{i}-r_{i} q_{i}\right) \frac{B}{2-\alpha_{i}}
$$

where $\alpha_{i}=d A / d \eta_{i}<1$ (see proof of Proposition 1 in Appendix A.2.1). From (15) we see that the regional perspective may call for a negative downstream subsidy - in effect, a tax on downstream emissions - to the extent that the domestic emissions effects are more important than foreign emissions (the first and the second term in (15)), and terms-of-trade effects are small or negative (the last term in (15)).

To allow a more straightforward comparison with the global optimum, let us consider a symmetric Nash equilibrium with identical policies and parameters. This simplifying assumption eliminates net terms-of-trade effects, and implies:

$$
\begin{aligned}
& \eta=\frac{(1-r)(\beta-3)}{3 r} \tau<0 \\
& \gamma=\frac{3(M-\rho r)-(3+2 \beta)(1-r) \tau}{6 r}
\end{aligned}
$$

As expected, the downstream subsidy is negative, whereas the sign of the upstream subsidy depends on the renewable standard and the shadow price of emissions. The first part of the numerator must be positive, and so the upstream subsidy will have to be positive for sufficiently low $\tau$ or sufficiently high $r$, implying relatively low emissions costs.

The reason why the individual region tends to prefer upstream subsidies over downstream subsidies (or tax upstream supply less than downstream demand) is the strategic effect. That 
is, an upstream subsidy in Region 1 leads to reduced upstream supply from Region 2, which benefits the upstream producer in the former region. However, we cannot rule out the possibility that the single region will tax upstream supply more than downstream demand. This will actually be the case if $\tau$ and $\beta$ are sufficiently high. The reason is that an upstream tax reduces downstream output and hence emissions in both regions. We conclude:

6 When the downstream sectors are regulated with a renewable standard, the optimal strategy for a single country is to tax downstream use of renewables (to discourage the emissions associated with additional output) and to subsidize upstream abatement equipment to the extent that downstream value added exceeds the additional emissions costs.

We can also express the Nash equilibrium in the following way (by subtracting the equation for $d W_{i} / d \eta_{i}=0$ from the equation for $\left.d W_{i} / d \gamma_{i}=0\right)$ :

$$
w_{N}-\eta_{i, N}=\rho+\tau_{i}\left(\frac{1}{r_{i}}-1\right), i=\{1,2\}
$$

Thus, if each region applies the global cost of carbon as its emissions value even if it discounts foreign emissions by applying a $\beta_{i}<1$ - the Nash equilibrium will replicate the global optimum! This is seen by comparing (17) with (12). To understand this somewhat counterintuitive result, observe first that from a global perspective it does not matter whether subsidies are implemented upstream or downstream; rather, it is the sum of the subsidies that matters. Consider the Nash solution for $\gamma$ and $\eta$ above. Assume that we increase both subsidies in Region 1 in such a way that the net effect on the technology price $w$ is zero 
(this is possible since the two subsidies have opposite price effects). Then we know that the welfare in Region 2 is unaffected by this change in subsidies. ${ }^{12}$ Hence, since welfare in Region 1 does not increase (starting from a Nash solution it cannot), neither does global welfare increase, given that emissions are valued by the same rate. The same argument obviously holds if we reduce the subsidies. Thus, the Nash solution must be optimal also from a global perspective.

We state this result in the following proposition:

7 When the downstream sectors are regulated with a renewable standard, the optimal subsidy combination for individual regions in a noncooperative equilibrium is also optimal from a global perspective, if both regions value domestic emissions by the globally optimal emissions price.

\subsubsection{Unilateral regional subsidies}

Suppose instead that Region 2 has no additional subsidies $\left(\gamma_{2}=\eta_{2}=0\right)$. Then the optimal subsidies for Region 1 again imply that $w-\eta_{1}=\rho+\tau_{1}\left(\frac{1}{r_{1}}-1\right)$ (see (17)); however, this will not hold for Region 2, so the optimum will not be reached.

Given the algebraic complexity of the solution, consider again the fully symmetric case,

\footnotetext{
${ }^{12}$ The downstream market is obviously unaffected when the technology price is unchanged, and we can show that upstream supply is also unaffected.
} 
aside from the asymmetric subsidies. The unilateral policy for Region 1 then is:

$$
\begin{aligned}
\eta_{1}^{U} & =\frac{M-r \rho-(6-\beta)(1-r) \tau}{6 r} \\
\gamma_{1}^{U} & =\frac{M-r \rho-\frac{(6+5 \beta)}{7}(1-r) \tau}{\frac{12}{7} r}
\end{aligned}
$$

Both subsidies will be positive for low emissions values, but as the costs of carbon become larger, the downstream subsidy will turn negative sooner. Furthermore, the weight placed on foreign emissions $\beta$ has opposite effects: it tends to boost the downstream subsidy and temper the upstream subsidy, in both cases seeking to raise the technology price and decrease foreign emissions.

\section{3 $\quad$ Restricting upstream subsidies}

Here, we consider the effects of a limitation on the use of upstream manufacturing subsidies, such as by WTO disciplines, leaving only downstream deployment subsidies available.

From (12), we know that a global planner setting subsidies in both regions can achieve the optimal allocation with only downstream policies. The regional Nash equilibrium in this case is different, however. A unique solution can be derived. The first-order conditions for the downstream subsidies (15) still hold, but the global technology price lacks the influence of the upstream subsidies. Since the asymmetric solution is complex, consider first the symmetric version (i.e., $r_{i}=r, \tau_{i}=\tau, \eta_{i}=\eta, \beta_{i}=\beta$, and since $\gamma_{i}=0, w=(M / r+2 \rho+\eta) / 3$ ). Here, with only the downstream subsidy, we can show that: 


$$
w_{N}^{\text {no } \gamma}-\eta_{i, N}^{\text {no } \gamma}=\frac{3 M+10 \rho r+2(5-\beta) \tau(1-r)}{13 r}
$$

Next, consider the case in which both regions value emissions at the social cost of carbon (i.e., $\tau_{i}=\tau_{G}, \beta_{i}=1$; the case in which the Nash equilibrium replicated the social optimum when both instruments were present). Subtracting the optimal net downstream price, we see then that

$$
w_{N}^{\mathrm{no} \gamma}-\eta_{i, N}^{\mathrm{no} \gamma}-\left(\rho+\tau_{G}\left(\frac{1}{r}-1\right)\right)=\frac{3(M+\rho r)+5 \tau_{G}(1-r)}{13 r}
$$

This expression is positive as long as $\tau_{G}$ is not too high. ${ }^{13}$ Thus, comparing with (12), we see that the net downstream product price tends to be higher than optimal in the Nash equilibrium when regions are restricted from using upstream subsidies, even if they value emissions at the global social cost of carbon. In this case, when the regions value emissions correctly from a global perspective, banning the use of upstream subsidies reduces welfare.

On the other hand, in this scenario, the equilibrium net price is decreasing as the undervaluation of emissions increases; thus, at some $\tau<\tau_{G}$, the net downstream price of renewable equipment in the Nash equilibrium without upstream subsidies may reach the optimal solution, and below that, it will be too low. If emissions are unvalued completely, then $w_{N}^{\text {no } \gamma}-\eta_{i, N}^{\text {no } \gamma}=(3 M+10 \rho r) /(13 r)=\rho+3(M-\rho r) /(13 r)>\rho=w_{N}-\eta_{i, N} ;$ in other words, for a given valuation of emissions, the net downstream product price will always be higher in

\footnotetext{
${ }^{13}$ Note the optimal output quantity in (11), which we assume to be positive, implies from the numerator that $M+\rho r+\tau_{G}(1-r)>0$.
} 
the absense of upstream emissions subsidies. Whether this result is welfare improving then depends on the degree of undervaluation.

Together, these results reveal that it is not clear whether a ban on upstream subsidies is welfare improving.

Finally, we note that when only one of the regions has a downstream policy, and neither have an upstream policy, neither the global planner nor the strategic regional planner can achieve their optimum.

\section{Conclusion}

Our analysis has demonstrated that the effects of subsidizing renewable energy technology depend on whether subsidies are provided upstream or downstream. An important difference for carbon leakage and strategic effects is that the price of technology equipment is reduced with upstream subsidies but increased with downstream subsidies. Furthermore, renewable energy subsidies can combat different kinds of market failures. One is the emissions externality, which occurs from the use of nonrenewable energy sources in the downstream market. Another is an upstream market failure, in this case due to market power in the emerging upstream industry; in subsequent work, we also consider other upstream market failures, such as from knowledge spillovers or network externalities.

Given the different effects of the subsidies on global equipment prices, the emissions consequences are strongly influenced by the form of environmental regulations in the downstream sectors. With a binding renewable energy standard already in place, lowering the cost 
of renewable energy allows the expansion of nonrenewable energy, and thereby the expansion of emissions.

We find that from a global welfare perspective, with symmetric policies across countries, the choice between upstream and downstream subsidies does not matter. Market power upstream calls for positive subsidies. However, subsidies will enhance total energy production and thus lead to higher emissions due to the fixed renewable standard. Thus, optimal subsidies may be either positive or negative. More generally, the global planner would differentiate downstream subsidies to shift renewable energy use where it expands emissions to a lesser extent, and otherwise upstream subsidies are used, without geographic preference, to align downstream net-of-subsidy prices with their social costs.

From a national welfare perspective, we find that upstream subsidies are preferred over downstream subsidies. In fact, the Nash equilibrium between two identical countries involves taxing technology downstream, and subsidising (or taxing to a lesser extent) technology sales upstream. The reason is that downstream subsidies benefit both domestic and foreign technology suppliers, whereas upstream subsidies only benefit the former.

Still, it is unclear in this context whether upstream subsidies should be viewed as problematic in and of themselves. We show that the Nash equilibrium among competing regions can be optimal from a global perspective, as long as each country values domestic emissions by the global social cost of carbon. Indeed, disallowing upstream subsidies in this case results in a Nash equilibrium with higher net prices for renewable energy equipment and less deployment than is optimal. Hence, it seems that industrial policy issues may not on their 
own call for global coordination of technology subsidies. Of course, in a more heterogeneous world where regions also undervalue the damages from emissions, it is less clear to what extent self-interested strategic behavior, including upstream subsidies, improves outcomes. Toward this end, empirically calibrated models may help answer the question of whether the market-correcting benefits of upstream subsidies outweigh the protectionist costs.

Finally, we must emphasize the importance of the climate policy context when considering green industrial policy. With a reliance on renewable energy standards for decarbonization, the effects of supplementary policies on leakage work in the opposite direction than is usually postulated, since here expanding renewable energy allows a proportionate expansion of nonrenewable energy. Other work shows that if carbon taxes are used instead, supplementary policies that expand renewable energy tend to crowd out nonrenewable energy ([9]). However, this fact tends to enhance the preference for upstream subsidies, as they reduce both foreign and domestic emissions, while downstream subsidies would lead to carbon leakage.

\section{References}

[1] Birol, F. and P. Olerjarnik (2012): Will China Lead the World into a Clean-energy Future? Economics of Energy \&6 Environmental Policy 1 (1), 5-10.

[2] Böhringer, C. and K.E. Rosendahl (2010): Green Serves the Dirtiest. On the Interaction between Black and Green Quotas, Journal of Regulatory Economics 37, 316-325.

[3] Brown, S.P.A. and H.G. Huntington (2010): Reassessing the Oil Security Premium, RFF DP 10-05, Resources for the Future. 
[4] Buchholz, W. and K. A. Konrad (1994): Global Environmental Problems and the Strategic Choice of Technology, Journal of Economics, Springer Science \& Business Media B.V. 60, 299-321.

[5] David, M. and B. Sinclair-Desgagné (2005): Environmental Regulation and the EcoIndustry, J. Regulatory Econom. 28, 141-155.

[6] De Gorter, H. and D.R. Just (2010): The Social Cost and Benefits of Biofuels: The Intersection of Environmental, Energy and Agricultural Policy, Applied Economic Perspectives and Policy 32, 4-32.

[7] Eggert, H. and M. Greaker (2014): Promoting Second Generation Biofuels: Does the First Generation Pave the Road?, Energies 7: 1-16

[8] European Union Environmental Policy Statement (2006), http://europa.eu.int/comm/environment/.

[9] Fischer, C. (2015): Strategic Subsidies for Green Goods. Resources for the Future working paper.

[10] Fischer, C. (2010): Renewable Portfolio Standards: When Do They Lower Energy Prices? The Energy Journal 31(1), 101-119.

[11] Fischer, C. and S. Charnovitz (2015): Canada - Renewable Energy: Implications for WTO Law on Green and Not-so-Green Subsidies, World Trade Review 14 (02): 177210. .

[12] Fischer, C. and R.G. Newell (2008): Environmental and Technology Policies for Climate Mitigation, Journal of Environmental Economics and Management 55, 142-162. 
[13] Fischer, C. and L. Preonas (2010): Combining Policies for Renewable Energy: Is the Whole Less Than the Sum of Its Parts? International Review of Environmental and Resource Economics 4 (1): 51-92.

[14] Fischer, C., M. Greaker, and K. E. Rosendahl (2014): Robust Policies Against Emission Leakage: The Case for Upstream Subsidies, CESifo Working Paper Series No. 4742.

[15] Gerlagh, R., S. Kverndokk and K.E. Rosendahl (2009): Optimal Timing of Climate Change Policy: Interaction Between Carbon Taxes and Innovation Externalities, Environmental and Resource Economics 43, 369-390.

[16] Gerlagh, R., S. Kverndokk and K.E. Rosendahl (2014): The optimal time path of clean energy R\&D policy when patents have finite lifetime, Journal of Environmental Economics and Management 67, 2-19.

[17] Golombek, R. and M. Hoel (2004): Unilateral Emissions Reductions and Cross-Country Technology Spillovers, Advances in Economic Analysis $\&$ Policy 4 (2), Article 3.

[18] Greaker, M. and K. E. Rosendahl (2008): Environmental policy with upstream pollution abatement technology firms, J. Environ. Econom. Management 56, pp. 246-259.

[19] Nemet, G.F. (2009): Demand-pull, technology-push, and government-led incentives for non-incremental technical change, Research Policy 38, 700-709.

[20] OECD (2011): Interactions Between emissions Trading Systems and Other Overlapping Policy Instruments, General Distribution Document, Environment Directorate, OECD, Paris, www.oecd.org/env/taxes

[21] Palmer, K., A. Paul and M. Woerman (2011): Federal Policies for Renewable Electricity. 
Impacts and Interactions, RFF DP 10-53, Resources for the Future.

[22] Pillai U. and J. McLaughlin (2011): A model of competition in the solar panel industry, Energy Economics 40, 32-39

[23] Requate T. (2005): Timing and Commitment of Environmental Policy, Adoption of New Technology, and Repercussions on R\&D, Environmental and Resource Economics 31, 175-199.

[24] Statista (2015): Total installed capacity of wind energy worldwide from 2000 to 2013, The Statistics Portal, Statista. http://www.statista.com/statistics/272813/marketshare-of-the-leading-wind-turbine-manufacturers-worldwide/

[25] Stranlund, J. K. (1996): On the Strategic Potential of Technological Aid in International Environmental Relations, Journal of Economics, Springer Science \& Business Media B.V. 64, 1-22.

[26] Taylor, M. (2008): Beyond technology-push and demand-pull: Lessons from California's solar policy, Energy Economics 30, 2829-2854.

[27] World Trade Organization 2011. Harnessing trade for sustainable development and a green economy, Geneva, Switzerland. 


\section{A Appendix}

\section{A.1 Derivation of expressions in Section 2}

The representative firm maximizes the following profit function:

$$
\pi_{i}=\left(p_{i}-\left(w-\eta_{i}\right) r_{i}\right) q_{i}-\left(\left(1-r_{i}\right) q_{i}\right)^{2} / 2 .
$$

From the first order condition with respect to $q_{i}$, we obtain the supply of the downstream product:

$$
q_{i}=\left(p_{i}-\left(w-\eta_{i}\right) r_{i}\right) /\left(1-r_{i}\right)^{2} .
$$

In equilibrium, supply must equal demand:

$$
\left(p_{i}-\left(w-\eta_{i}\right) r_{i}\right) /\left(1-r_{i}\right)^{2}=\frac{M-p_{i}}{\varepsilon}
$$

Solving for $p_{i}$, we obtain:

$$
p_{i}=\frac{\left(1-r_{i}\right)^{2} M+\varepsilon r_{i}\left(w-\eta_{i}\right)}{\left(1-r_{i}\right)^{2}+\varepsilon} .
$$

Equation (3) then follows. 


\section{A.2 Proofs of Propositions 1-3}

To prove the propositions, remember that the intercept and slope of the upstream demand function in (4) are given by:

$$
\begin{aligned}
& A=\frac{r_{1} R_{2}\left(M+\eta_{1} r_{1}\right)+r_{2} R_{1}\left(M+\eta_{2} r_{2}\right)}{\left(r_{1}\right)^{2} R_{2}+\left(r_{2}\right)^{2} R_{1}} ; \\
& B=\frac{R_{1} R_{2}}{\left(r_{1}\right)^{2} R_{2}+\left(r_{2}\right)^{2} R_{1}} .
\end{aligned}
$$

where $R_{i}=\left(\left(1-r_{i}\right)^{2}+\varepsilon\right)$.

\section{A.2.1 Proof of Proposition 1}

Proof. The proposition follows directly from (6):

$$
\frac{d w}{d \gamma_{i}}=-\frac{1}{3}<0
$$

and

$$
\frac{d w}{d \eta_{1}}=\frac{d w}{d A} \frac{d A}{d \eta_{1}}=\alpha_{i} \frac{1}{3}>0
$$

where

$$
\alpha_{i}=\frac{d A}{d \eta_{i}}=\left(\frac{\left(r_{i}\right)^{2}\left(\left(1-r_{j}\right)^{2}+\varepsilon\right)}{\left(r_{i}\right)^{2}\left(\left(1-r_{j}\right)^{2}+\varepsilon\right)+\left(r_{j}\right)^{2}\left(\left(1-r_{i}\right)^{2}+\varepsilon\right)}\right)=\frac{\left(r_{i}\right)^{2}}{R_{i}} B<1 .
$$




\section{A.2.2 Proof of Proposition 2}

Proof. The proposition follows directly from (5):

$$
\begin{aligned}
& \frac{d y_{i}}{d \gamma_{i}}=\frac{2}{3 B}>0 \\
& \frac{d y_{j}}{d \gamma_{i}}=-\frac{1}{3 B}<0 \quad(i \neq j)
\end{aligned}
$$

while

$$
\frac{d y_{i}}{d \eta_{i}}=\frac{d y_{j}}{d \eta_{i}}=\frac{\alpha_{i}}{3 B}=\frac{\left(r_{i}\right)^{2}}{3 R_{i}}>0
$$

Note that the expressions can alternatively be represented in proportion to the input price effects in Proposition 1:

$$
\begin{aligned}
& \frac{d y_{i}}{d \gamma_{i}}=-\frac{2}{B} \frac{d w}{d \gamma_{i}}>0 ; \quad \frac{d y_{j}}{d \gamma_{i}}=\frac{1}{B} \frac{d w}{d \gamma_{i}}<0 \\
& \frac{d y_{i}}{d \eta_{i}}=\frac{d y_{j}}{d \eta_{i}}=\frac{1}{B} \frac{d w}{d \eta_{i}}>0 .
\end{aligned}
$$

\section{A.2.3 Proof of Proposition 3}

Proof. From (3), $q_{i}=\left(M-r_{i}\left(w-\eta_{i}\right)\right) / R_{i}$. From this expression, we see that the downstream output effect of a change in the upstream subsidy is proportional to its effect on the input 
price. Using (18) we get:

$$
\begin{gathered}
\frac{d q_{i}}{d \gamma_{i}}=-\frac{r_{i}}{R_{i}} \frac{d w}{d \gamma_{i}}=\frac{1}{3} \frac{r_{i}}{R_{i}} ; \\
\frac{d q_{j}}{d \gamma_{i}}=-\frac{r_{j}}{R_{j}} \frac{d w}{d \gamma_{i}}=\frac{1}{3} \frac{r_{j}}{R_{j}} \\
\frac{d q_{i}}{d \gamma_{i}}=\frac{d q_{i}}{d \gamma_{j}}=\frac{1}{3} \frac{r_{i}}{\left(\left(1-r_{i}\right)^{2}+\varepsilon\right)}>0 \\
\frac{d q_{i}}{d \eta_{i}}=\frac{r_{i}}{R_{i}}\left(1-\frac{d w}{d \eta_{i}}\right) ; \frac{d q_{j}}{d \eta_{i}}=-\frac{r_{j}}{R_{j}} \frac{d w}{d \eta_{i}} \\
\frac{d y_{i}}{d \gamma_{i}}=\frac{2}{3 B}=-\frac{2}{B} \frac{d w}{d \gamma_{i}} ; \frac{d y_{j}}{d \gamma_{i}}=-\frac{1}{3 B}=\frac{1}{B} \frac{d w}{d \gamma_{i}} \\
\frac{d y_{i}}{d \eta_{i}}=\frac{\alpha_{i}}{3 B}=\frac{d y_{j}}{d \eta_{i}}=\frac{1}{B} \frac{d w}{d \eta_{i}}
\end{gathered}
$$

and (19) we get:

$$
\frac{d q_{i}}{d \eta_{1}}=\left(1-\frac{\Delta}{3}\right) \frac{r_{i}}{\left(\left(1-r_{i}\right)^{2}+\varepsilon\right)}>0
$$

and

$$
\frac{d q_{j}}{d \eta_{1}}=-\frac{\Delta}{3} \frac{r_{j}}{\left(\left(1-r_{j}\right)^{2}+\varepsilon\right)}<0
$$

where $\Delta=\frac{\left(r_{i}\right)^{2}\left(1-r_{j}\right)^{2}+\varepsilon\left(r_{i}\right)^{2}}{\left(r_{i}\right)^{2}\left(1-r_{j}\right)^{2}+\varepsilon\left(r_{i}\right)^{2}+\left(r_{j}\right)^{2}\left(1-r_{i}\right)^{2}+\varepsilon\left(r_{j}\right)^{2}} \leq 1$. Note that $\Delta=\frac{1}{2}$ when $r_{1}=r_{2}$, and $\Delta=1$ when $r_{j}=0$. Since $\Delta \leq 1$, total downstream output in the two regions increases when $\eta_{1}$ increases. 


\section{A.3 Summary Table of Relationships}

$$
\begin{array}{rlrl}
q_{i} & =\frac{M-r_{i}\left(w-\eta_{i}\right)}{R_{i}} ; & y_{i} & =\frac{A-\rho+2 \gamma_{i}-\gamma_{j}}{3 B} \\
\frac{d q_{i}}{d \gamma_{i}} & =-\frac{r_{i}}{R_{i}} \frac{d w}{d \gamma_{i}} ; & \frac{d q_{j}}{d \gamma_{i}} & =-\frac{r_{j}}{R_{j}} \frac{d w}{d \gamma_{i}} \\
\frac{d q_{i}}{d \eta_{i}} & =\frac{r_{i}}{R_{i}}\left(1-\frac{d w}{d \eta_{i}}\right) ; & \frac{d q_{j}}{d \eta_{i}} & =-\frac{r_{j}}{R_{j}} \frac{d w}{d \eta_{i}} \\
\frac{d y_{i}}{d \gamma_{i}} & =\frac{2}{3 B}=-\frac{2}{B} \frac{d w}{d \gamma_{i}} ; & & \frac{d y_{j}}{d \gamma_{i}}=-\frac{1}{3 B}=\frac{1}{B} \frac{d w}{d \gamma_{i}} \\
\frac{d y_{i}}{d \eta_{i}}=\frac{1}{B} \frac{d w}{d \eta_{i}}=\frac{\alpha_{i}}{3 B}=\frac{\left(r_{i}\right)^{2}}{3 R_{i}} & \frac{d y_{j}}{d \eta_{i}}=\frac{1}{B} \frac{d w}{d \eta_{i}}=\frac{\alpha_{i}}{3 B}=\frac{\left(r_{i}\right)^{2}}{3 R_{i}} \\
\frac{d w}{d \eta_{i}}=\frac{\alpha_{i}}{3} & \frac{d w}{d \gamma_{i}}=-\frac{1}{3} \\
R_{i}=\left(1-r_{i}\right)^{2}+\varepsilon & \alpha_{i}=\frac{\left(r_{i}\right)^{2}}{R_{i}} B<1 \\
A=\frac{r_{1} R_{2}\left(M+\eta_{1} r_{1}\right)+r_{2} R_{1}\left(M+\eta_{2} r_{2}\right)}{\left(r_{1}\right)^{2} R_{2}+\left(r_{2}\right)^{2} R_{1}} ; & B & =\frac{R_{1} R_{2}}{\left(r_{1}\right)^{2} R_{2}+\left(r_{2}\right)^{2} R_{1}}
\end{array}
$$

